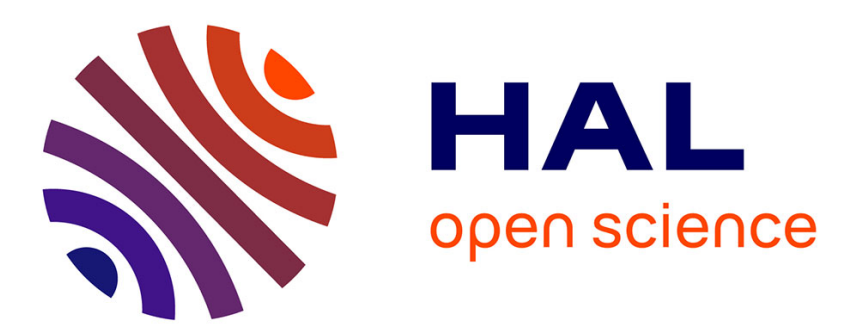

\title{
Influence de différents facteurs sur la morphogenèse et la croissance de fragments d'organes de pomme de terre cultivés in vitro
}

\author{
Sylvain Chaillou, Line Rossignol-Bancilhon
}

\section{- To cite this version:}

Sylvain Chaillou, Line Rossignol-Bancilhon. Influence de différents facteurs sur la morphogenèse et la croissance de fragments d'organes de pomme de terre cultivés in vitro. Agronomie, 1985, 5 (8), pp.701-708. hal-00884802

\section{HAL Id: hal-00884802 https://hal.science/hal-00884802}

Submitted on 1 Jan 1985

HAL is a multi-disciplinary open access archive for the deposit and dissemination of scientific research documents, whether they are published or not. The documents may come from teaching and research institutions in France or abroad, or from public or private research centers.
L'archive ouverte pluridisciplinaire HAL, est destinée au dépôt et à la diffusion de documents scientifiques de niveau recherche, publiés ou non, émanant des établissements d'enseignement et de recherche français ou étrangers, des laboratoires publics ou privés. 


\title{
Influence de différents facteurs sur la morpho- genèse et la croissance de fragments d'organes de pomme de terre cultivés in vitro
}

\author{
Sylvain CHAILLOU \& Line ROSSIGNOL-BANCILHON $\left(^{*}\right)$ \\ Institut National Agronomique Paris-Grignon, Laboratoire de Physiologie végétale, 16, rue Claude-Bernard, \\ F 75231 Paris Cedex 05 \\ (*) Laboratoire d'étude et d'exploitation du polymorphisme végétal, associé au C.N.R.S., Bât. 360, Université \\ Paris-Sud, Centre d'Orsay, F 91405 Orsay Cedex
}

\begin{abstract}
Des fragments de feuilles (limbes et pétioles) et des nœuds de germes de 3 variétés de pomme de terre (Solanum tuberosum L.) sont cultivés in vitro sur le milieu de Murashige et Skoog durant 6 à 10 semaines. Chez les fragments de feuilles, un rapport molaire AIA/BAP égal à 1,5 permet d'obtenir une organogenèse de bourgeons rapide, dès la troisième semaine, et importante en proportion du nombre d'explants mis en culture. Lorsque le rapport AIA/BAP est égal à 15, on observe une néoformation de racines, mais qui reste très faible par rapport à celle des bourgeons. La croissance des fragments de feuilles est exponentielle et présente une première phase rapide durant les 2 premières semaines, suivie d'une seconde plus lente. La masse de matière sèche accumulée est beaucoup plus forte au cours de l'organogenèse de bourgeons (2,5 fois à la septième semaine). Un fort degré d'incubation des tubercules de départ et un milieu de culture non favorable peuvent expliquer la faible croissance des explants durant l'organogenèse de racines. La variété " Ackersegen " s'avère supérieure à "Sirtema » et " Bintje " pour la production et pour la croissance de bourgeons néoformés. Les nœuds de germes, cultivés sans hormone, développent de jeunes plantes qui s'enracinent rapidement.
\end{abstract}

Mots clés additionnels : Organogenèse, fragments de feuilles, nœuds de germes. vitro.

Leaf fragments (blade and petiole) and sprout nodes of three cultivars of potato (Solanum tuberosum L.) were cultured in vitro on MURASHIGE and SKOOG medium for 6-10 weeks. For leaf fragments, an IAA/BAP ratio of 1.5 (molarity) induced rapid shoot organogenesis from the third week in a high proportion of cultured explants. At an IAA/BAP ratio of 15 , formation of new roots was observed, but to a very limited extent by comparison with shoot organogenesis. Growth of leaf fragments was exponential, with a rapid phase followed by a slow one. Dry matter accumulation was greater during shoot organogenesis ( 2.5 times in the 7 th week). Excessively long incubation of the original tubers, and the unsuitable nutrient medium, may explain the poor growth of the explants during root organogenesis. Cultivar "Ackersegen" was found to be superior to Sirtema and Bintje for production and growth of newly formed shoots. Sprout nodes cultured without hormones developed young plants which quickly rooted.

Additional key words : Organogenesis, leaf fragments, sprout nodes.

\section{ABRÉVIATIONS}

AIA : acide indolacétique.

AIB : acide indolbutyrique.

BAP : 6-benzylaminopurine.

GA3 : acide gibbérellique 3 .

MS : matière sèche.

\section{INTRODUCTION}

Chez la pomme de terre, des néoformations ont été récemment obtenues par de nombreux auteurs à partir de fragments d'organes cultivés in vitro. L'intérêt s'est surtout porté sur les néoformations de bourgeons qui peuvent prendre naissance à partir de fragments 
de tiges (WANG \& HUANG, 1975 ; QURAISHI et al., 1979 ; HUSSEY \& STACEY, 1981), de feuilles (BEHNKE, 1975 ; ROEST \& BOKELMANN, 1976 ; WEBB et al., 1983) et de tubercules (LAM, 1975, 1977 ; SKIRVIN et al., 1975 ; JARRET et al., 1980 ; KIKUTA \& OKAZAWA, 1982).

Ces travaux montrent en outre la nécessité de préciser l'influence, sur les phénomènes d'organogenèse in vitro, de certains facteurs liés à la plante sur laquelle sont prélevés les explants. Ainsi en est-il de la variété, du type d'organe mis en culture et de l'état physiologique des tubercules de semences.

Les tubercules subissent en effet, au cours de leur stockage, une évolution physiologique dont le siège est dans les tissus de réserve et qui influence à tout instant le devenir des bourgeons. Elle peut être résumée de la façon suivante (PERENNEC \& MADEC, 1980) :

Après la récolte, les tubercules sont en repos végétatif, période pendant laquelle ils ne peuvent germer. Puis vient une phase où la croissance des germes a lieu, ceux-ci pouvant alors développer une nouvelle plante si les conditions de milieu le permettent. Enfin se déroule une phase de non-croissance des germes, dont le terme ultime est la formation de tubercules-fils par les germes, sans développement préalable de feuillage. C'est le phénomène de boulage (MADEC, 1956).

Le stade de tubérisation des germes a été appelé stade d'incubation, notamment par MADEC \& PERENNEC (1955), MADEC (1966) et JoliveT (1969). De même a été définie la phase d'incubation, qui est la période s'écoulant entre le début de la germination du tubercule et la formation d'ébauches de tubercules-fils par les germes.

A un moment donné de sa vie, au cours de sa conservation, le tubercule sera donc dans un certain état physiologique, que l'on définit par son degré d'incubation ou encore par son âge physiologique (PERENNEC \& MADEC, 1960 ; JOLIVET, 1969). Le degré d'incubation dépend du temps écoulé depuis la récolte, des conditions de température subies pendant le stockage et aussi de la variété. QURAISHI et al.
(1979) ont montré l'importance du facteur incubation sur le comportement des explants in vitro.

Nous avons étudié l'action de ces 3 facteurs (variété, type d'organe mis en culture, état physiologique des tubercules de semences) sur la morphogenèse et la croissance des explants au cours des premières semaines de culture in vitro.

\section{MATÉRIELS ET MÉTHODES}

\section{A. Matériel végétal}

1) Trois variétés de pomme de terre (Solanum tuberosum L.) ont été choisies. Elles diffèrent en particulier par leur précocité de récolte : «Sirtema », hâtive, « Bintje », demi-hâtive, «Ackersegen », tardive, et aussi par d'autres caractères, notamment leur état physiologique.

2) Les explants mis en culture sont, d'une part, des fragments de limbes et de pétioles, c'est-à-dire des organes ayant achevé leur croissance et, d'autre part, des nœuds de germes, donc des organes jeunes porteurs de méristèmes au sein d'un bourgeon axillaire.

3) Les tubercules de semence :

Les tubercules de départ sont fournis par la Fédération Nationale des Producteurs de Plants de Pommes de terre (FNPPP). Leur état sanitaire a été éprouvé et ils sont en particulier indemnes des principaux virus.

Ces tubercules sont d'abord traités à la « rindite ", peu après la récolte, afin de lever leur repos végétatif. La « rindite » est un mélange synergique constitué de 7 volumes de monochlorhydrine du glycol, 3 volumes de dichloro-1,2 éthane et 1 volume de tétrachlorure de carbone (DENNY, 1945). Après un certain temps de conservation qui détermine leur degré d'incubation (tabl. 1) ils sont placés dans 2 conditions :

- Les uns sont cultivés en serre, en lumière naturelle, sur de la «vermiculite» arrosée quotidiennement avec une solution nutritive commerciale Cofaz.

TABLEAU 1

Protocole expérimental. Principaux facteurs intervenant dans les trois expérimentations réalisées. Experimental protocol. Principal factors involved in the three experiments.

\begin{tabular}{|c|c|c|c|}
\hline Régulateurs de croissance & \multicolumn{2}{|c|}{$\begin{array}{l}\text { Fragments } \\
\text { de limbes el pétioles }\end{array}$} & $\begin{array}{l}\text { Nœuds } \\
\text { de germes }\end{array}$ \\
\hline $\begin{array}{l}\text { AIA } \\
\text { BAP } \\
\text { GA3 } \\
\text { Rapport molaire }\end{array}$ & $\begin{array}{l}6.10^{-6} \mathrm{M} \\
4.10^{-6} \mathrm{M} \\
3.10^{-5} \mathrm{M}\end{array}$ & $\begin{array}{c}6.10^{-6} \mathrm{M} \\
4.10^{-7} \mathrm{M} \\
0\end{array}$ & $\begin{array}{l}0 \\
0 \\
0\end{array}$ \\
\hline$\frac{\text { AIA }}{\text { BAP }}$ & 1,5 & 15 & - \\
\hline Organogenèse & Bourgeons & Racines & Développement \\
\hline Etat d'incubation des tubercules de départ & Faible (a) & Fort (a) & Faible (a) \\
\hline Dénomination de chaque expérimentation & Programme « Bourgeons» & Programme « Racines» & Culture de germes \\
\hline
\end{tabular}

(a) Les tubercules à faible degré d'incubation ont été conservés à $4{ }^{\circ} \mathrm{C}$ durant 1 à 3 mois. Le lot fortement incubé a été conservé durant 9 mois 
Ces tubercules vont donner des plantes à partir desquelles, au bout d'un mois à un mois et demi, des feuilles seront prélevées pour la culture in vitro, dans la portion médiane de la tige, rangs 6 à 8 partir de la base.

- Les autres tubercules sont conservés à l'obscurité durant 3 semaines, à la température ambiante du laboratoire. Ils vont produire des germes qui seront utilisés pour la culture in vitro.

\section{B. Désinfection}

Les organes prélevés, feuilles et germes, sont désinfectés durant $20 \mathrm{mn}$ par de l'hypochlorite de calcium à 5 p. 100 (masse/volume), additionné de quelques gouttes d'un agent mouillant, le «teepol ». Suivent alors 2 rinçages à l'eau distillée stérile, l'un de $5 \mathrm{mn}$, l'autre de $10 \mathrm{mn}$.

\section{Explants}

Les explants de limbes sont des disques de diamètre $13 \mathrm{~mm}$ prélevés à l'aide d'un emporte-pièce. Les pétioles sont sectionnés en cylindres de longueur $10 \mathrm{~mm}$ qui sont redécoupés en deux dans le sens de la longueur. Les germes sont découpés en explants de longueur $10 \mathrm{~mm}$ pourvus d'un bourgeon. La portion la plus proche du tubercule est éliminée, à cause de risques plus importants de contamination par des microorganismes.

Les explants sont cultivés en tubes à essai (hauteur $150 \mathrm{~mm}$, diamètre $20 \mathrm{~mm}$ ) contenant $15 \mathrm{ml}$ de milieu. Les disques foliaires sont déposés la face ventrale au contact du milieu; pour les fragments de pétioles, la surface sectionnée est placée du côté du milieu. Les nœuds de germes sont mis verticalement, l'extrémité basale légèrement enfoncée dans le milieu.

\section{Milieu de culture}

Les éléments minéraux et les addenda organiques sont ceux précisés par MURASHIGE \& SKOOG (1962) auxquels on ajoute 0,8 p. 100 d'agar et 2 p. 100 de saccharose. Le pH est ajusté à 5,8. Le milieu est stérilisé à l'autoclave à $110^{\circ} \mathrm{C}(0,5$ bar $)$ durant $20 \mathrm{mn}$.

\section{E. Protocole expérimental}

Trois séries d'expérimentations sont réalisées : organogenèse de bourgeons, de racines et développement de bourgeons axillaires. Les principaux facteurs, notamment les doses d'hormones employées, sont donnés dans le tableau 1.

\section{F. Conditions de culture}

La culture in vitro se déroule en salle climatisée à $23 \pm 1{ }^{\circ} \mathrm{C}$, sous un éclairement continu fourni par des tubes fluorescents et des lampes à incandescence sous-voltées. L'intensité du rayonnement photosynthétiquement actif mesurée au niveau des cultures est de $80 \mu \mathrm{E} . \mathrm{s}^{-1} \cdot \mathrm{m}^{-2}$.

\section{G. Prélèvement des explants}

Des explants sont récoltés chaque semaine. Après pesée de la matière fraîche, la masse de matière sèche est déterminée après séchage à $110^{\circ} \mathrm{C}$ durant $48 \mathrm{~h}$.

\section{RÉSULTATS}

\section{A. Type de morphogenèse}

\section{Explants de feuilles}

a) Bourgeons néoformés :

Un cal se forme au cours de la $1^{\text {re }}$ semaine au niveau des surfaces sectionnées des explants. Les bourgeons néoformés apparaissent dans ce cal et ils sont visibles à l'œil nu dès la $3^{\mathrm{e}}$ semaine. Il n'y a que peu de différences entre les variétés chez les explants de limbes pour lesquels 90 à 100 p. 100 des fragments ont produit des bourgeons à la $5^{\mathrm{e}}$ semaine (fig. $1 \mathrm{~B}$ ). Chez les explants de pétioles, en revanche, les variétés diffèrent entre elles (fig. 1 A) : la proportion de 100 p. 100 d'explants avec néoformations est atteinte plus rapidement chez "Ackersegen » (4 semaines) que chez "Sirtema » (6 semaines) et «Bintje » (7 semaines).

Les bourgeons néoformés sont nombreux (10 à 15 par tube) et vigoureux (fig. 2 A). Leur croissance est rapide et ils s'enracinent parfois en fin de culture.

\section{b) Racines néoformées:}

Un cal se forme dès la $1^{\text {re }}$ semaine mais il est moins abondant que dans le cas précédent. Les racines néoformées apparaissent dès la $2^{\mathrm{e}}$ semaine et le nombre d'explants en cause n'augmente pas ensuite (fig. $1 \mathrm{C}$ et $\mathrm{D})$. Cette organogenèse est beaucoup moins importante que celle des bourgeons.

Ainsi, la proportion de 100 p. 100 d'explants ayant formé des racines n'est jamais atteinte au cours de cette culture (fig. $1 \mathrm{C}$ et $\mathrm{D}$ ). Le pourcentage de fragments de limbes enracinés est très faible (fig. $1 \mathrm{D})$. De plus, les racines ne sont apparues qu'en petit nombre ( 3 ou 4 par tube au plus) (fig. 2 B) et elles n'ont eu qu'une faible croissance au cours de l'expérience. Elles prennent naissance en dehors du cal, directement sur le fragment, et elles sont couvertes de poils absorbants (fig. 2 B). Dès qu'elles atteignent le milieu de culture, leur croissance s'arrête et leur extrémité se renfle en massue.

Nous constatons que la variété «Sirtema » n'a pratiquement pas produit de néoformations racinaires, à l'inverse de "Bintje » et d'“Ackersegen » (fig. $1 \mathrm{C}$ et D).

\section{Nouds de germes}

Les phénomènes observés sont différents de ceux décrits sur les fragments de limbes et de pétioles. Ces derniers sont constitués quasi-uniquement de cellules différenciées dont certaines vont subir une réactivation mitotique et se multiplier, alors que les nœuds de germes, organes jeunes, portent des bourgeons contenant un méristème et des ébauches de feuilles. Mais avant que ne se développent ces ébauches par élonga- 

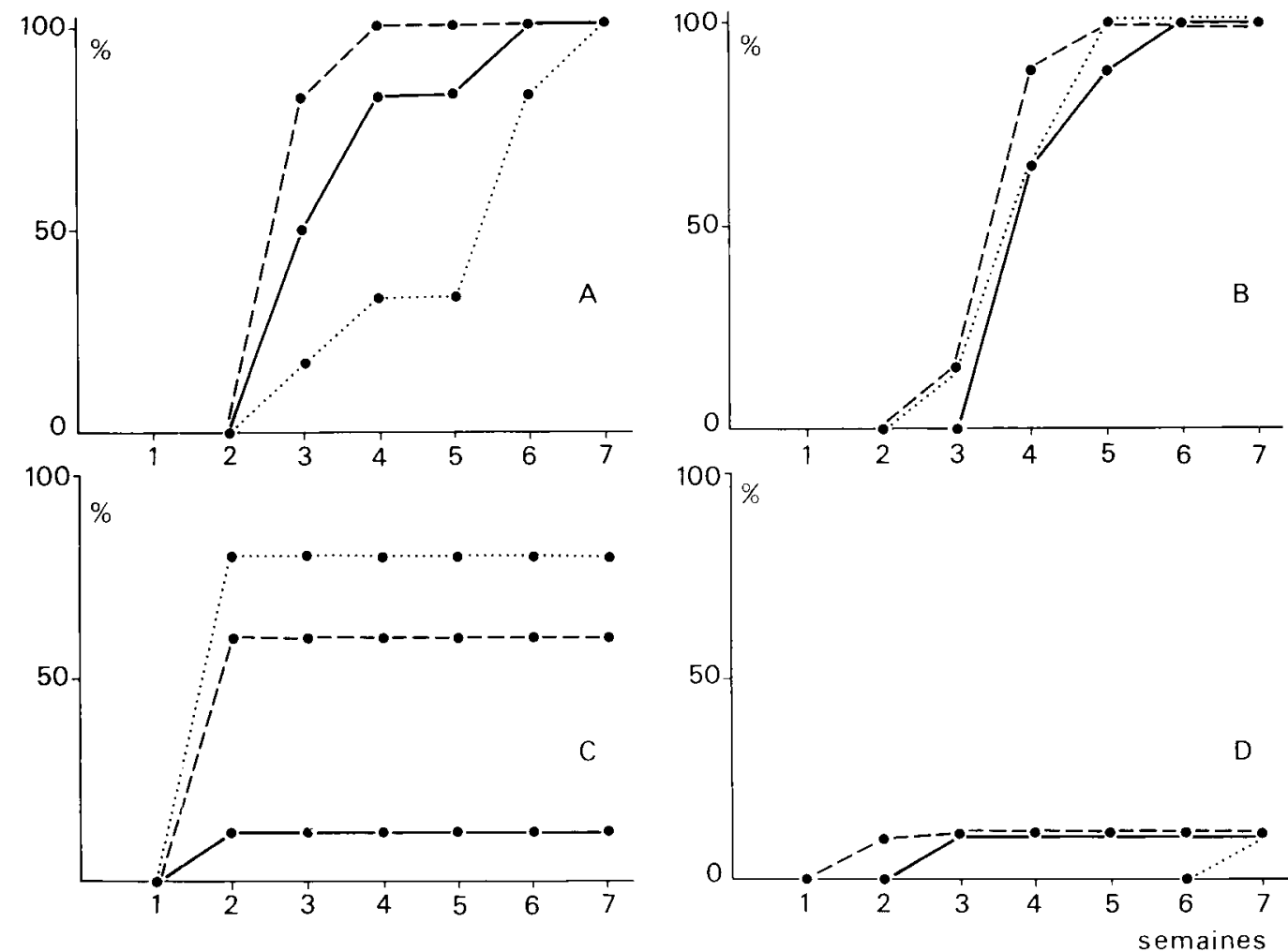

Figure 1

Culture in vitro de fragments de pétioles ( $A$ et $C$ ) et de limbes foliaires (B et $D)$ de pomme de terre, variétés "Sirtema ", "Bintje », "Ackersegen ". Pourcentage d'explants ayant produit des néoformations caulinaires $(A$ et $B$, 6 explants par lot) ou des néoformations racinaires ( $C$ et $D, 10$ explants par lot) au cours du temps. __ : Sirtema ; ..... : Bintje ; - . : Ackersegen.

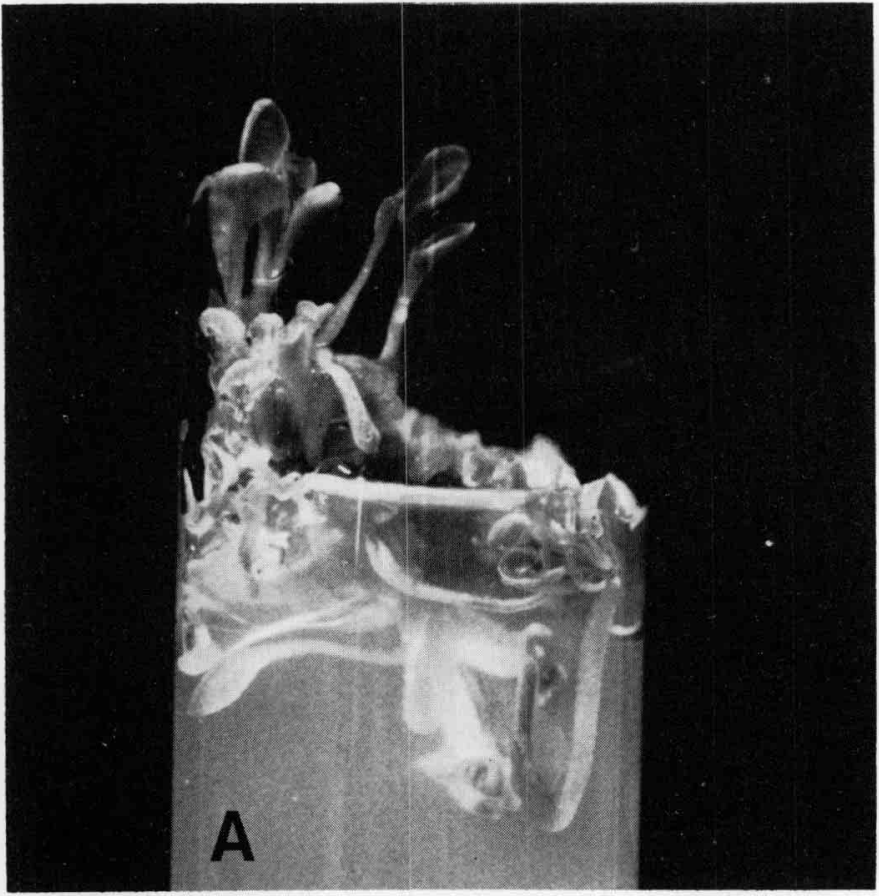

Figure 2

A. Aspect d'un fragment de pétiole de pomme de terre, variété «Ackersegen », cultivé in vitro pendant un mois (programme "Bourgeons"). On remarque un grand nombre de bourgeons néoformés.

B. Aspect d'un fragment de pétiole de pomme de terre, variété "Bintje », cultivé in vitro pendant 13 j (programme « Racines»). On note l'apparition de 3 racines néoformées.
In vitro culture of fragments of potato petioles ( $A$ and $C$ ) and leaf blades ( $B$ and D) cultivars 'Sirtema', 'Bintje', 'Ackersegen'. Percent of explants producing new shoots ( $A$ and $B, 6$ explants per lot) or new roots $(C$ and $D, 10$ explants per lot) with time.

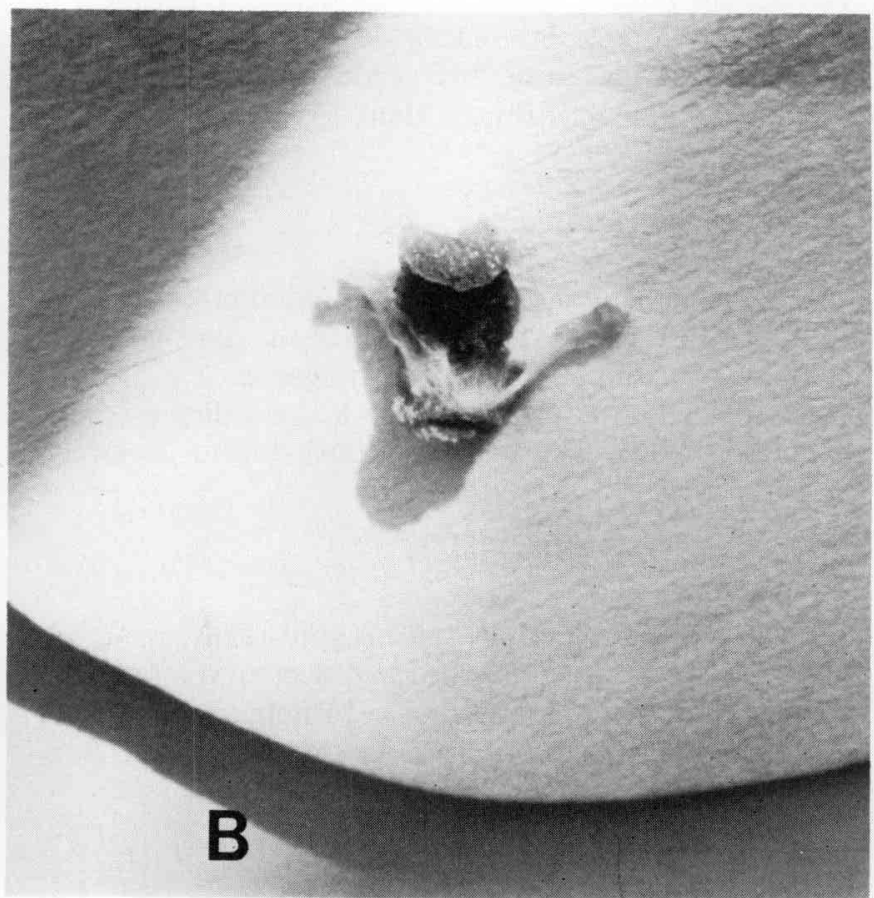

A. Appearance of a potato petiole fragment, cv. 'Ackersegen', cultured in vitro for 1 month for shoot organogenesis. Many neoformed shoots can be seen.

B. Appearance of a potato petiole fragment, cv. 'Bintje', cultured in vitro for 13 days for root organogenesis. 3 neoformed roots can be seen. 
tion, vont se former les champs morphogénétiques qui vont donner les racines adventives, comme cela a été observé sur la vigne (FAvRE, 1973).

Les fragments de germes donnent alors rapidement, sans intervention de substances hormonales exogènes, une jeune plante qui s'enracine dès les premières heures de la culture et il n'y a aucune production de cal.

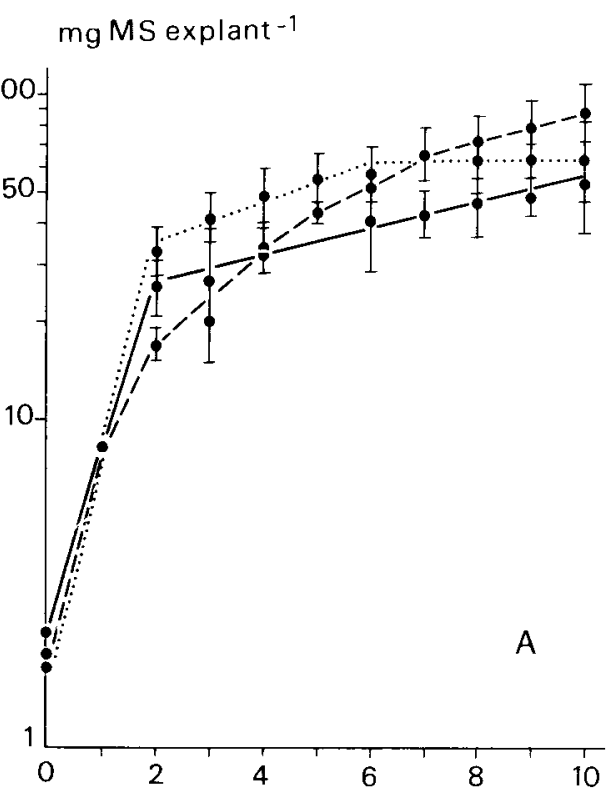

Figure 3

Programme «Bourgeons". Production de matière sèche (mg par explant) en coordonnées semi-log par des fragments de pétioles $(A)$ et de limbes $(B)$ de pomme de terre cultivés in vitro. Chaque point correspond à la moyenne de 6 données. Intervalles de confiance au niveau 0,1. _ : Sirtema ; .... : Bintje ; . . : Ackersegen.

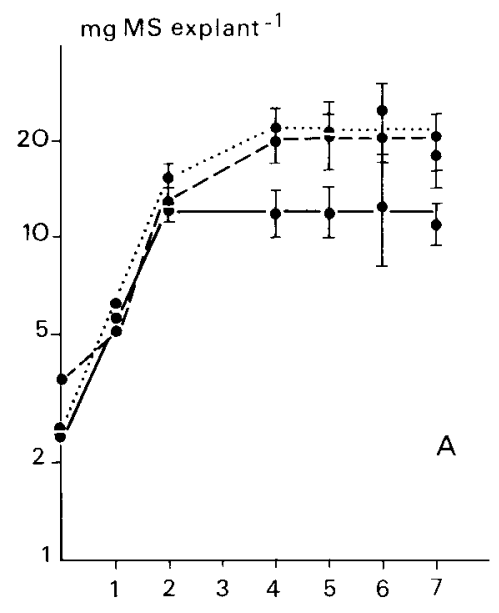

Figure 4

Programme « Racines ». Production de matière sèche (mg par explant) en coordonnées semi-log par des fragments de pétioles $(A)$ et de limbes $(B)$ de pomme de terre cultivés in vitro. Chaque point correspond à la moyenne de 10 données. Intervalles de confiance au niveau de 0,05. ‥ Sirtema ;.... : Bintje ; . . : Ackersegen.

\section{B. Croissance}

\section{Explants de feuilles}

Les courbes de croissance, représentées en coordonnées semi-logarithmiques, font ressortir 2 phases bien distinctes dans la production de matière sèche des explants sur la durée des expériences (fig. 3 et 4).

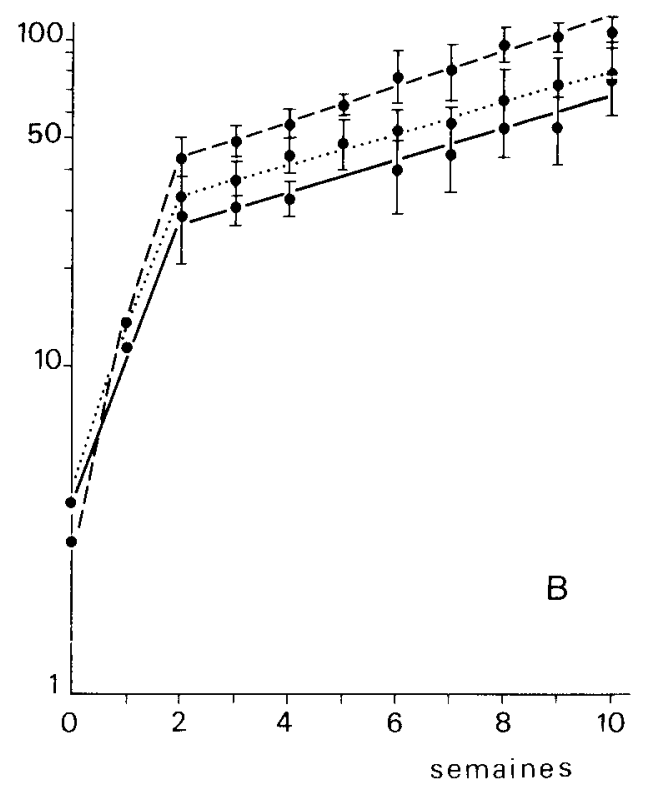

Shoot organogenesis on fragments of potato petioles $(A)$ and leaf blades $(B)$ cultured in vitro. Growth of the explants (dry weight) on semi-log coordinates. Each point is the mean of 6 replicates. Error bars at 0.1 .

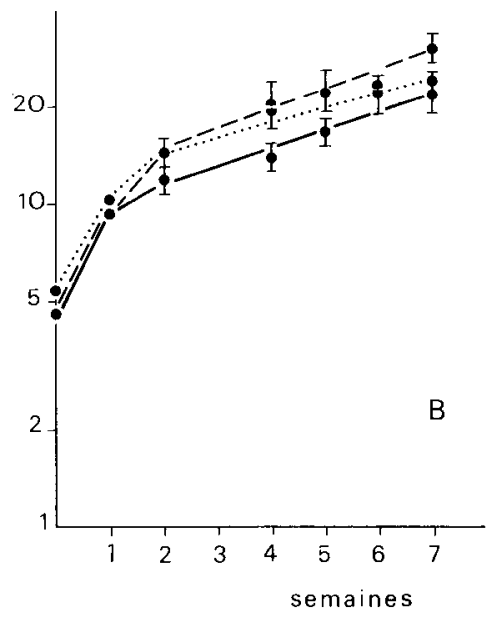

Root organogenesis on fragments of potato petioles $(A)$ and leaf blades ( $B)$ cultured in vitro. Growth of the explants (dry weight) in semi-log coordinates. Each point is the mean of 10 replicates. Error bars at 0.05 . 
La $1^{\text {re }}$ phase dure 2 semaines : elle et caractérisée par une croissance rapide, le temps de doublement étant de 0,5 semaine pour le programme «Bourgeons» et de 1 semaine pour le programme « Racines " (cf. tabl. 1). Il en résulte qu'au cours de cette dernière culture les explants ont accumulé beaucoup moins de matière sèche que dans le cas de l'organogenèse de bourgeons : respectivement 20 et $50 \mathrm{mg}$ à la $7^{\mathrm{e}}$ semaine.

La $2^{\mathrm{e}}$ phase, qui s'étend dans la plupart des cas jusqu'à la fin de l'expérience, correspond à une croissance plus lente, le temps de doublement étant de 5 à 7 semaines (fig. $3 \mathrm{~A}$ 《Sirtema », fig. $3 \mathrm{~B}$ et 4 B).

Dans certains cas, cette $2^{\mathrm{e}}$ phase est courte, 2 à 3 semaines, et est suivie d'une $3^{e}$ durant laquelle la croissance s'arrête. Ainsi en est-il pour les fragments de pétioles chez «Bintje » au cours du programme «Bourgeons » (fig. $3 \mathrm{~A}$ ) et pour les 3 variétés au cours du programme "Racines" (fig. 4 A). Dans ce dernier cas, chez «Sirtema », la $2^{\mathrm{c}}$ phase n'existe pas, la croissance s'arrête dès la fin de la $2^{\mathrm{e}}$ semaine, cette variété restant alors inférieure de $2 / 3$ aux 2 autres pour la production de matière sèche.

Une autre différence notable entre les variétés est la supériorité de «Ackersegen» par rapport à «Sirtema » et «Bintje », au cours de l'organogenèse de bourgeons. Ceci s'observe en fin d'expérience pour les explants de pétioles (fig. $3 \mathrm{~A}$ ) et dès la $2^{\mathrm{e}}$ semaine chez les fragments de limbes (fig. $3 \mathrm{~B}$ ), “Ackersegen » accumulant $1 / 3$ de matière sèche de plus que les 2 autres variétés.

\section{Nouds de germes}

La cinétique de croissance est très différente de celle des explants de feuilles. On observe une $1^{\text {re }}$ phase de

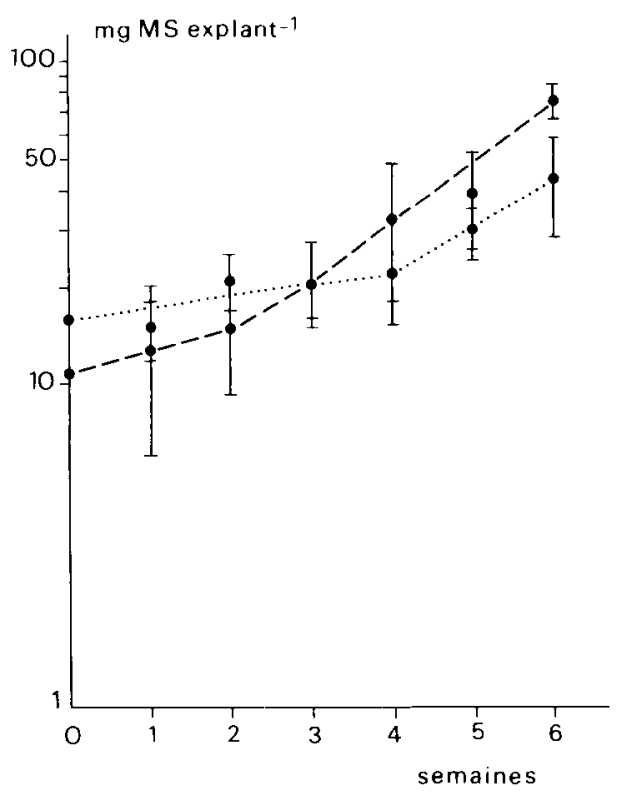

Figure 5

Production de matière sèche (mg par explant) en coordonnées semilog par des nouds de germes de pomme de terre cultivés in vitro. Chaque point correspond à la moyenne de 10 données. Intervalles de confiance au niveau $0,05$. — : Sirtema ; ....: Bintje ; - . - : Ackersegen.

Growth (dry weight) in semi-log coordinates of potato sprout nodes cultured in vitro. Each point is the mean of 10 replicates. Error bars at 0.05 . croissance assez lente, avec un temps de doublement de 5 semaines chez "Ackersegen ", de 8 semaines chez «Bintje » (fig. 5). Cette $1^{\text {re }}$ phase dure respectivement 2 et 4 semaines. Puis une $2^{\mathrm{e}}$ phase commence, plus rapide (temps de doublement de 2 semaines) (fig. 5). L'expérience a été arrêtée au cours de cette $2^{\mathrm{e}}$ phase. La variété "Ackersegen » s'avère là encore supérieure à «Bintje »: 40 p. 100 de matière sèche de plus à la $6^{\mathrm{e}}$ semaine.

\section{DISCUSSION}

\section{A. Croissance et morphogenèse}

\section{Explants de feuilles}

La croissance est exponentielle en 2 phases, la $1^{\text {re }}$ rapide, la $2^{\mathrm{e}}$ lente. Une exception toutefois : les fragments de pétioles de la variété «Ackersegen » ont plutôt une cinétique de croissance linéaire $(r=0,99)$ au cours du programme «Bourgeons».

La croissance est plus faible au cours du programme «Racines »; elle peut même s'arrêter. Une explication possible de ce phénomène est proposée plus loin.

La $1^{\text {re }}$ phase de croissance, rapide, correspond à la formation du cal, qui se produit dès la $1^{\text {re }}$ semaine. Puis apparaissent les néoformations : racines la $2^{\mathrm{e}}$ semaine, bourgeons la $3^{\mathrm{e}}$ semaine. Le ralentissement de la croissance, marqué par le début de la $2^{\mathrm{e}}$ phase, est concomitant de l'organogenèse de bourgeons. Mais il a lieu 1 semaine plus tard dans le cas de la néoformation de racines. De plus, ce ralentissement s'observe aussi chez les fragments de limbes au cours du programme « Racines », alors que l'organogenèse a été pratiquement nulle.

Le déclenchement de la $2^{\mathrm{e}}$ phase de croissance, lente, ne semble donc pas forcément lié à l'organogenèse.

Un autre phénomène pourrait intervenir : l'épuisement des réserves internes de l'explant, qui ne dépendrait plus alors que des éléments du milieu nutritif. Il a été montré (CHAILlOU, 1984) que l'absorption des éléments majeurs par ce type d'explants commence au cours de la $1^{\text {re }}$ semaine de culture. Cette absorption se superpose à l'utilisation des réserves mais elle n'est sans doute pas suffisante pour maintenir, à elle seule, la croissance à un rythme aussi rapide que celui du début de culture. Le passage à l'autotrophie complète de l'explant serait donc marqué par un ralentissement de la croissance, que nous observons sur nos courbes. Dans le cas de l'organogenèse de bourgeons, ce ralentissement correspond peut-être à l'arrêt du développement du cal, relayé par la croissance des bourgeons néoformés qui apparaissent à ce moment. Mais nous n'avons pas d'arguments expérimentaux en faveur de cette hypothèse. A notre connaissance, ce type de cinétique de croissance biphasique n'a pas été observé jusqu'ici.

\section{Nouds de germes}

La croissance est exponentielle mais, à l'inverse des explants de feuilles, elle commence lentement puis s'accélère, cette $2^{\mathrm{e}}$ phase n'étant pas achevée à la fin de l'expérience. 
Durant la phase relativement lente, se produit le début de la morphogenèse : développement des racines adventives et émergence des premières feuilles du bourgeon axillaire. Ces événements n'accroissent que faiblement la masse de matière sèche des explants. Il ne se forme pas de cal, le milieu étant dépourvu de régulateurs de croissance. Puis, avec l'élongation de la tige provenant de ce même bourgeon, la croissance devient beaucoup plus importante : c'est la $2^{\mathrm{e}}$ phase. L'explant se comporte alors comme une jeune plante, pour laquelle nous observons le début d'une cinétique de croissance classique de type sigmoïde (ROLAND, 1982).

\section{B. Effet variété et degré d'incubation (pour les explants de feuilles)}

Ces 2 facteurs sont liés, la vitesse d'incubation d'un tubercule dépendant de la variété. Les différences observées entre les variétés en culture in vitro sont en fait le résultat de l'action de 2 facteurs : génotype et âge physiologique du tubercule de semence.

1) Pour le programme "Racines ", les explants sont prélevés sur des plantes issues de tubercules fortement incubés. L'âge physiologique avancé de ces tubercules a dû retentir sur la vigueur (en la diminuant) des plantes auxquelles ils ont donné naissance. Les parties aériennes, notamment, ont pu subir un ralentissement, voire un arrêt de leur croissance, concomitant d'un déclenchement de la tubérisation (MADEC, 1966 ; JOLIVET, 1969 ; PERENNEC \& MADEC, 1980). Cet arrêt de croissance se sera produit d'autant plus tôt que la variété est plus précoce (à date de plantation égale). Nous avons donc mis en culture in vitro des fragments d'un feuillage qui se trouvait probablement très affecté dans ses potentialités de croissance et ceci encore plus pour la variété «Sirtema", plus précoce et qui incube plus rapidement que «Bintje » et "Ackersegen ».

Les propriétés particulières de ces plantes, dont la croissance était presque inhibée, se seraient traduites in vitro au niveau des explants, par une morphogenèse et une croissance faibles, notamment chez " Sirtema ». Ainsi peut s'expliquer l'infériorité de cette variété par rapport aux 2 autres, au cours de cette expérience (programme « Racines »).

Nous retrouvons ici l'importance déjà signalée par QURAISHI et al. (1979) de l'âge physiologique des tubercules de départ, autrement dit leur degré d'incubation, sur les phénomènes de néoformations d'organes in vitro.

Mais nous relevons une contradiction entre nos observations et les précédentes (QURAISHI et al., 1979) où une fréquence moindre d'explants avec néoformations était obtenue avec le lot de tubercules le moins incubé. Dans notre cas (programme "Racines »), ce sont des tubercules très incubés qui ont entraîné une croissance et une morphogenèse faibles, par rapport au programme «Bourgeons » où les tubercules de départ étaient peu incubés.

Cette contradiction pourrait être levée par des expériences mettant en jeu une gamme de tubercules d'âge physiologique différent.
2) Pour le programme "Bourgeons », la supériorité observée in vitro chez la variété «Ackersegen» par rapport aux deux autres nous semble plus liée à son génome qu'à l'âge physiologique des tubercules puisque les plantes de départ sont issues de tubercules peu incubés, donc nullement inhibées dans leur croissance.

"Ackersegen » est connue pour l'importance, au champ, de son développement végétatif par rapport à "Sirtema » et " Bintje ». Nous retrouvons, semble-til, en culture in vitro la vigueur particulière de cette variété (caractère génétique) qui se traduit par une croissance et une organogenèse fortes. Cette idée est soutenue par le fait que les nœuds de germes de cette variété " Ackersegen " ont une croissance plus forte que chez "Bintje» (fig. 5), toujours à partir de tubercules peu incubés.

3) La différence que nous observons dans ces phénomènes in vitro entre programmes «Bourgeons » et " Racines » pourrait aussi être une question de milieu de culture au niveau hormonal. Le milieu que nous avons utilisé pour la néoformation de bourgeons est sans doute bien meilleur que celui employé pour obtenir des racines, à l'inverse des expériences précédentes où QURAISHI et al. (1979) obtenaient plus facilement des racines que des bourgeons néoformés. Ces variations sont à relier aux différences de nature et de doses d'hormones utilisées, résumées ci-dessous.

\begin{tabular}{|c|c|c|c|}
\hline & 0 & $\mathrm{is} \mathrm{mo}$ & \\
\hline $\begin{array}{l}\text { Organ } \\
\text { de bot }\end{array}$ & $\begin{array}{l}\text { ogenèse } \\
\text { urgeons }\end{array}$ & $\begin{array}{r}\text { Orga } \\
\text { de }\end{array}$ & $\begin{array}{l}\text { enèse } \\
\text { ines }\end{array}$ \\
\hline $\begin{array}{l}\text { Expériences } \\
\text { décrites } \\
\text { ici }\end{array}$ & $\begin{array}{l}\text { Expériences } \\
\text { précédentes } \\
\text { (QuRAISHI } \\
\text { et al., 1979) }\end{array}$ & $\begin{array}{c}\text { Expériences } \\
\text { décrites } \\
\text { ici }\end{array}$ & $\begin{array}{l}\text { Expériences } \\
\text { précédentes } \\
\text { (QURAISHI } \\
\text { et al., 1979) }\end{array}$ \\
\hline
\end{tabular}

Auxine AIA $6.10^{-6}$ AIB $10^{-6}$ AIA $6.10^{-6}$ AIB $10^{-6}$ Cytokinine BAP 4.10-6 BAP $2.10^{-7}$ BAP $4.10^{-7}$ BAP $10^{-7}$ Gibbérelline GA3 $3.10^{-5}-$ -

Les doses utilisées ici sont plus élevées que pour les expériences précédentes (QURAISHI et al., 1979), ce qui a été favorable à l'organogenèse de bourgeons, mais pas à celle de racines. Pour obtenir des bourgeons, nous ajoutons une forte dose de gibbérelline, tout comme ROEST \& BOKELMANN (1976) et WEBB et al. (1983).

La production en grand nombre de bourgeons néoformés sur cal à partir de fragments de limbes et pétioles, notamment chez la variété "Ackersegen » encore peu utilisée in vitro, peut intéresser les producteurs de plants et les améliorateurs de la pomme de terre.

Reçu le 19 septembre 1984 Accepté le 29 mars 1985.

\section{REMERCIEMENTS}

Nous tenons à remercier M. E. Jolivet (I.N.R.A., Versailles) pour sa lecture critique du manuscrit et ses conseils précieux. Nos remerciements vont également à MM. J. MERLET et J. QUEMENER (FNPPP) pour leur collaboration et aussi pour avoir fourni les tubercules de semence. 


\section{RÉFÉRENCES BIBLIOGRAPHIQUES}

Behnke M., 1975. Regeneration in Gewebekulturen einiger dihaploider Solanum tuberosum Klone. Z. Pflanzenzüchtg., 75, 262-265.

Chaillou S., 1984. Observations sur la nutrition minérale de fragments d'organes de pomme de terre (Solanum tuberosum L.) cultivés in vitro. Thèse Doct. Ing., INA P.G., Paris, 118 p.

Denny F. E., 1945. Synergistic effect of three chemicals in the treatment of dormant potato tubers to hasten germination. Contrib. Boyce Thomson Inst., 14, 1-14.

Favre J. M., 1973. Effets corrélatifs de facteurs internes et externes sur la rhizogenèse d'un clone de vigne (Vitis riparia $\times$ Vitis rupestris) cultivé in vitro. Rev. gén. Bot., 80, 279-361.

Hussey G., Stacey N. J., 1981. In vitro propagation of potato (Solanum tuberosum L.). Ann. Bot., 48, 787-796.

Jarret R. L., Hasegawa P. L., Erickson H. T., 1980. Effect of medium components on shoot formation from cultured tuber discs of potato. J. Am. Soc. Hortic. Sci., 105, 238-242.

Jolivet E., 1969. Physiologie de la tubérisation. Ann. Physiol. Vég., 11, 256-301.

Kikuta Y., Okazawa Y., 1982. Shoot-bud formation and plantlet regeneration in potato tuber tissue cultured in vitro. J. Fac. Agr. Hokkaido Univ., 61, 166-179.

Lam S. L., 1975. Shoot formation in potato tuber dises in tissue culture. Am. Potato J., 52, 103-106.

Lam S. L., 1977. Plantlet formation from potato tuber discs in vitro. Am. Potato J., 54, 465-468.

Madec P., 1956. La nature et les causes du boulage chez la pomme de terre. Ann. Amélior. Plantes, 6, 151-169.

Madec P., 1966. Croissance et tubérisation chez la pomme de terre. Bull. Soc. Fr. Physiol. Vég., 12, 159-173.
Madec P., Perennec P., 1955. Les possibilités d'évolution des germes de la pomme de terre et leurs conséquences. Ann. Amélior. Plantes, 5, 555-574.

Murashige T., Skoog F., 1962. A revised medium for rapid growth and bio-assays with tobacco tissue cultures. Physiol. Plant., 15, 473-497.

Perennec P., Madec P., 1960. Influence du tubercule sur la croissance et le développement du germe de pomme de terre. Ann. Physiol. vég., 2, 29-67.

Perennec P., Madec P., 1980. Age physiologique du plant de pomme de terre. Incidence sur la germination et répercussions sur le comportement des plantes. Potato Res., 23, 183-199.

Quraishi A., Rossignol-Bancilhon L., Nozeran R., 1979. Effet de l'origine du fragment sur la callogenèse et l'organogenèse in vitro chez Solanum tuberosum L., var. « BF 15 ». Ann. Amél. Plantes, 29, 639-663.

Roest S., Bokelmann G. S., 1976. Vegetative propagation of Solanum tuberosum L. in vitro. Potato Res., 19, 173-178.

Roland J. C., 1982. Croissance, 227-342. In P. Mazliak : « Croissance et développement ", Hermann, Paris, $465 \mathrm{p}$.

Skirvin R. M., Lam S. L., Janick J., 1975. Plantlet formation from potato callus in vitro. Hortscience, 10, 413.

Wang P. J., Huang L. C., 1975. Callus cultures from potatoes tissues and the exclusion of potato virus $\mathrm{X}$ from plants regenerated from stem tips. Can. J. Bot., 53, 2565-2567.

Webb K. J., Osifo E. O., Henshaw G. G., 1983. Shoot regeneration from leaflet discs of six cultivars of potato (Solanum tuberosum subsp. tuberosum). Plant Sci. Lett., 30, 1-8. 